\title{
Conhecimento em rede e a inteligência coletiva aplicada na ferramenta Scoop.it
}

\section{Resumo}

Com advento das novas tecnologias ocorrem mutações nos modos de comunicação e compartilhamento de saberes no ciberespaço. O tema dá ênfase às questões sobre cibercultura, delimitado à análise das práticas de inteligência coletiva no processo comunicacional da ferramenta Scoop.it, que implementa e compartilha informações no ciberespaço para geração de conhecimento em rede. $\mathrm{O}$ objetivo do trabalho consiste em refletir sobre a construção de um novo espaço antropológico ${ }^{3}$, no qual os seres humanos criam e compartilham conhecimento na internet, por meio da linguagem. A metodologia utilizada é de uma pesquisa exploratória, com análise qualitativa. A análise das informações direciona a resultados que apoiam o uso da inteligência coletiva no desenvolvimento da informática, que possibilita a potenciação da comunicação no meio virtual, privilegiando a cooperação na troca de informações entre os seres humanos.

Palavras-chave: Cibercultura; Inteligência Coletiva; Comunicação; Scoop.it.

\section{Resumen}

Con el advenimiento de las nuevas tecnologías, ocurren mutaciones en los modos de comunicación y compartimiento de saberes en el ciberespacio, delimitando el análisis de las prácticas de inteligencia colectiva en la y de la comunicación en la herramienta Scoop.it, que implementa y comparte informaciones en el ciberespacio para generar conocimiento red. El trabajo objetiva reflexionar acerca de la construcción de un nuevo espacio antropológico, en lo cual los seres humanos crean y comparten conocimientos en la internet, a través del lenguaje. La metodología utilizada es de una investigación exploratoria, con análisis cualitativa. El análisis de las informaciones nos direcciona a resultados que apoyan la inteligencia colectiva al desarrollo de la informática, que posibilita la potencialización de la comunicación en el medio virtual, privilegiando la cooperación en el intercambio de informaciones entre los seres humanos.

Palabras - clave: Cibercultura; Inteligencia Colectiva; Comunicación; Scoop.it.
Eliane Davila dos Santos ${ }^{1}$ Ernani Cesar de Freitas ${ }^{2}$

${ }^{1}$ Doutoranda e Mestre em Processos e Manifestações Culturais pela Universidade Feevale (2015); Especialista em Gestão de Serviços pela Unisinos (2003); Gestão de Pessoas pela

Unisinos (2001) e Administradora de Empresas pela Feevale (1997).

Trabalhou mais de vinte anos em instituições financeiras e atualmente é Bolsista de doutorado pela Prosup/ Capes em Processos e Manifestações

Culturais na Universidade Feeva-

le, dedicando-se às pesquisas da linguagem, comunicação e análise do discurso. Está afiliada à linha de pesquisa de Linguagens e Processos Comunicacionais que focaliza o processo de comunicação e sua institucionalização sob o ângulo da cultura e de suas manifestações. Desde 2016 é integrante do projeto de pesquisa Cultura, Comunicação e Trabalho: práticas linguageiras e a construção do sujeito e da identidade em situação de trabalho, com o objetivo de abordar a atividade

laboral mediante interface entre as noções de cultura, de comunicação e de linguagem e trabalho.

2 Pós-doutorado em Linguística Aplicada e Estudos da Linguagem - PUC-SP/LAEL (2011); Doutor em Letras, área de concentração Lingüística Aplicada (PUCRS/2006); Mestre em Lingüística Aplicada pela Universidade do Vale do Rio dos

Sinos (UNISINOS/2002). Possui graduação em LETRAS - Português/ Inglês e respectivas Literaturas, pelo Centro Universitario La Salle (1999).

Experiência na área de Letras, com

ênfase em Língua Portuguesa e

Linguística Aplicada, nos temas relacionados à linguagem e trabalho, 
Abstract

With the advent of new technologies, there have been changes in knowledge and communication sharing in cyberspace. The present theme emphasizes matters regarding cyberculture, delimitated to the analysis of collective intelligence in the communication process with Scoop.it, tool that is used for implementing and sharing information in the cyberspace for net knowledge generation. The aim of the work is to reflect about building a new anthropological space in which human beings create and share knowledge via internet through language. It is an exploratory research with qualitative analysis. The information analysis directs to results that support the use of collective intelligence for computer science development, making possible to maximize communication in the virtual environment, promoting cooperation in the exchange of information among human beings.

Key-words: Cyberculture; Collective intelligence; Communication; Scoop.it.

\section{Introdução}

A temática emerge da reflexão sobre os novos saberes que o ciberespaço disponibiliza para a construção do conhecimento na internet. Presenciamos no mundo contemporâneo uma nova forma de relações entre as pessoas e os saberes. A tecnologia permite a potencialização da comunicação e do conhecimento, simbolizando a presença do homem no ciberespaço. O tema surge a partir das reflexões sobre cibercultura, delimitado à análise das práticas de inteligência coletiva ${ }^{4}$ na e da comunicação na ferramenta Scoop.it ${ }^{5}$.

Como questão norteadora deste estudo, tem-se que as plataformas de criação e compartilhamento de informações podem gerar, por meio da linguagem, o compartilhamento de conhecimento da grande coletividade a serviço das pessoas e dos grupos sociais em rede. O objetivo do trabalho consiste em refletir sobre a construção de um novo espaço antropológico, no qual os seres humanos criam e compartilham conhecimento na internet por meio da linguagem. Para compor os estudos, utilizam-se os ensinamentos de Lemos (2013), Jenkins (2012), Kerckhove (1995). O marco teórico principal de análise da perspectiva da linguagem comunicacional é de Bakhtin (2000) e da inteligência coletiva é de Lévy (2011).

A análise das informações direciona a resultados que apoiam a inteligência coletiva no desenvolvimento da informática, que possibilita a potencialização da comunicação no meio virtual, privilegiando assim a cooperação de informações entre os seres humanos. Esse meio diversificado, heterogêneo e sem um centro controlador em que as plataformas constroem suas redes de inteligência coletiva, pode contribuir para melhorias sociais, de cultivo da inteligência individual e da inteligência em rede, uma vez que o ser humano é social e individual no uso da linguagem. A metodologia utilizada é de uma pesquisa exploratória com análise qualitativa.

As seções estão assim dispostas: primeiramente, um espaço dedicado às questões da linguagem na cibercultura, tendo como premissa que as texto e discurso, leitura e formação do leitor; na área da Comunicação e cultura: comunicação socio-organizacional, cultura e identidade. Cursou MBA Gestão Empresarial na UFRGS e MBA Executivo na FGV-RJ. Professor (Titular) de Ensino Superior na Universidade Feevale, Programa de Pós-graduação em

Processos e Manifestações Culturais, e professor permanente no PPG em Letras na Universidade de Passo Fundo (RS). Integrante de conselhos editorias e parecerista ad hoc de revistas acadêmicas. Membro da Associação de Linguística Aplicada do Brasil (ALAB), da Associação Brasileira de Linguística (ABRALIN); da AsociaciónLatinoamericana de Estudiosdel Discurso (ALED); da Asociación de Lingüística y Filología de América Latina (ALFAL); da AssociationAnalysedesDiscours de 1?Amérique Latine (ADAL/Paris); participante efetivo do GT ANPOLL- Linguagem, Enunciação e Trabalho. Trabalhou como funcionário do Banco do Brasil no período de janeiro/1975 a outubro/2002, onde exerceu diversos cargos comissionados na área da gestão; possui experiência como consultor organizacional em empresas e bancos, principalmente em unidades do Banco do Brasil no país e no exterior.

3 "É um sistema de proximidade (espaço) próprio do mundo humano (antropológico), e, portanto, dependente de técnicas, de significações, da linguagem, da cultura, das convenções, das representações e das emoções humanas". (LÉVY, 2011, p. 22).

4 A inteligência coletiva é "uma inteligência distribuída por toda parte, incessantemente valorizada, coordenada em tempo real, da qual resulta uma mobilização efetiva das competências" (LÉVY, 2011, p. 29).

5 Plataforma de implementação e compartilhamento de informações na internet. http://www.scoop.it/. 


\section{$\gamma_{\text {Rizoma }}$}

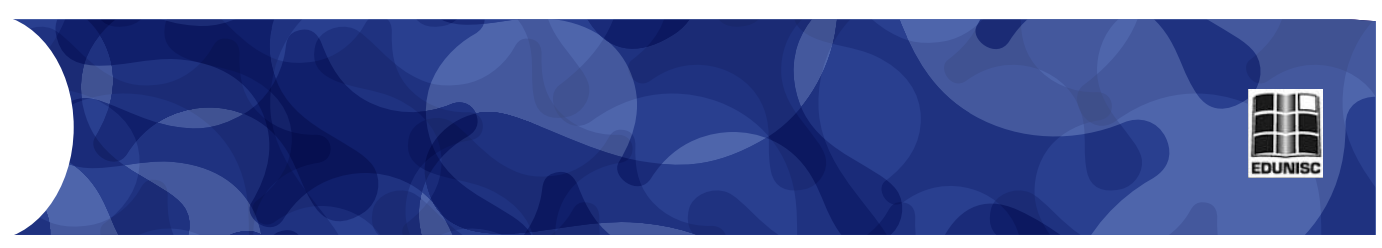

tecnologias favorecem o acesso à informação, num ambiente de interação comunicacional virtual. Na próxima seção, apresenta-se o conceito de inteligência coletiva como prática social no ciberespaço. Segue-se com as questões metodológicas e, em seguida, com a exposição de resultados e uma síntese da análise.

\section{A comunicação na cibercultura: a tecnologia como facilitadora e potencializadora de interações nos ciberespaços}

Pensar sobre cultura, segundo Bosi (1992), é buscar sua origem na palavra colo que significa, em latim "eu moro, eu cultivo". Preliminarmente, a palavra caracterizava as culturas agrícolas e, em seguida, o vocábulo passou a se referir ao conjunto de ideias e tradições de um povo. Logo depois, a palavra cultura passou a designar o cultivo dos ritos, cultos e tradições de um povo. A utilização do termo cultura em sua "conotação mais forte, a saber, como aquilo que se cultiva, que faz nascer, que dá forma" (LEMOS, 2013, p. 270) converge com o pensamento de Bosi (1992) e coloca a cibercultura como um conjunto de técnicas, práticas, atitudes, valores, modos de pensar, que se desenvolvem juntamente na internet.

Em meio a um novo ambiente de comunicação, que está interconectado mundialmente, a cibercultura constitui, no momento, a principal trilha e suporte de memória do ser humano. Conforme Lévy (2011), trata-se de um novo espaço de comunicação social, de organização, acesso e condução de informação e conhecimento. O que se percebe é que falar sobre cibercultura pressupõe uma menção ao termo "aldeia global", utilizado por McLuhan (1998), com que ele sugere que as tecnologias eletrônicas encurtam distâncias, espalham informações e catapultam o progresso tecnológico. Desta forma, pode-se dizer que o mundo passa a ser um pequeno vilarejo onde todos se conhecem e estão conectados, ou seja, uma "aldeia global".

Com a realidade da cibercultura e das novas tecnologias na internet, emerge o ciberespaço que diz respeito ao virtual, isto é, um espaço que permite uma potencialização da comunicação e das habilidades cognitivas do indivíduo. No ciberespaço, como na vida real, as alterações são relevantes na forma de pensar, nos relacionamentos e sociedade. Lévy (2011) afirma que este novo espaço de sociabilidade gera diferentes maneiras de se relacionar e que "a administração do ciberespaço, o meio de comunicação e de pensamento dos grupos humanos, será uma das principais áreas de atuação estética e política do próximo século" (LÉVY, 2011, p. 107).

Buscando caracterizar os espaços antropológicos de significação construídos pela cibercultura, pode-se dizer que eles nascem de espaços de interações. O processo da informação cede à linguagem um papel importante no ambiente virtual. "As sociedades que leem e escrevem atingem um nível de controle sobre a linguagem que lhes permite deter uma espécie de poder 

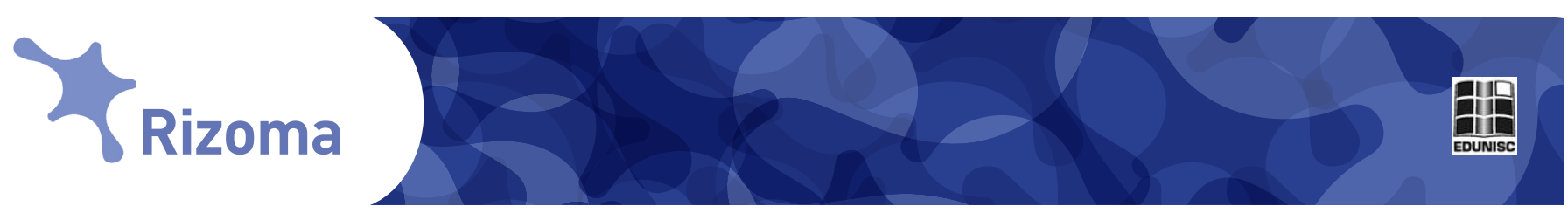

sobre seus destinos" (KERCKHOVE, 1995, p. 256). Acredita-se que a linguagem afeta diretamente os padrões de desenvolvimento da inteligência humana. A psicotecnologia ${ }^{6}$, na visão de Kerckhone (1995), permite o alargamento das nossas relações com o mundo, não somente pela extensão dos sentidos, mas pelo prolongamento do sistema nervoso e da formação da nossa consciência. Assim,

a finalidade do homem, ao falar, não é a de recortar, descrever, estruturar o mundo; ele fala em princípio, para se colocar em relação ao outro, porque disso depende a própria existência, visto que a consciência de si passa pela tomada de consciência do outro, pela assimilação do outro e ao mesmo tempo pela diferenciação com relação ao outro. (CHARAUDEAU, 2009, p. 41- 42).

Nessa perspectiva, acredita-se que as psicotecnologias possam levar o processo de consciência para dentro da mídia. Contudo, a interação, a capacidade que garante a autonomia individual, dentro da tendência de coletivização psicotecnológica, é ampliada pelos computadores e suas redes na internet. Esse ato de alargar o domínio cognitivo somente é motivado pelo encontro com o outro. $\mathrm{O}$ encontro com o outro remete a uma relação dialógica. Neste momento, traz-se à discussão Bakhtin ${ }^{7}$ (2002), ao considerar a língua dialogicamente e não dissociada dos parceiros do discurso. O discurso é uma prática da linguística no campo da comunicação e consiste em analisar a estrutura de enunciado e, a partir disso, entender as construções ideológicas aí presentes, assim como compreender a própria amplitude da linguagem do discurso. O pensamento bakhtiniano aponta para a relevância da concepção dialógica e, para a vertente pragmática, na segunda metade do século XX, que ocorra na linguística, o que estimulou os estudos do discurso. Ao se conceber a presença do outro no discurso, é possível produzir significados e admitir a dimensão comunicacional dos enunciados. De acordo com Fiorin (2008), a teoria bakhtiniana coloca o ser humano não completamente assujeitado aos discursos sociais. "No dialogismo incessante, o ser humano encontra espaço de sua liberdade e de seu inacabamento. Nunca ele é submetido completamente aos discursos sociais. A singularidade de cada pessoa no simpósio universal ocorre na interação viva das vozes sociais" (FIORIN, 2008, p. 28).

$O$ ambiente da internet, com todos os avanços tecnológicos de que dispomos, no que tange à comunicação e à interação, encontra apoio nas teorias de Bakhtin (2002), uma vez que essa concebe a linguagem como imanentemente social, nas práticas cotidianas, nas ações intersubjetivas. Ou seja, trata-se da integração dialógica do ser humano e da sociedade. A perspectiva dialógica de Bakhtin (2002) leva em conta não somente as vozes sociais, mas também as individuais. A maioria das opiniões dos indivíduos é social.

A cibercultura permite que o ser humano encontre espaço para revelar-se como ser social e individual. A consciência do ser humano constrói-se na comunicação social, ou seja, na relação dialógica proposta 


\section{$\gamma_{\text {Rizoma }}$}

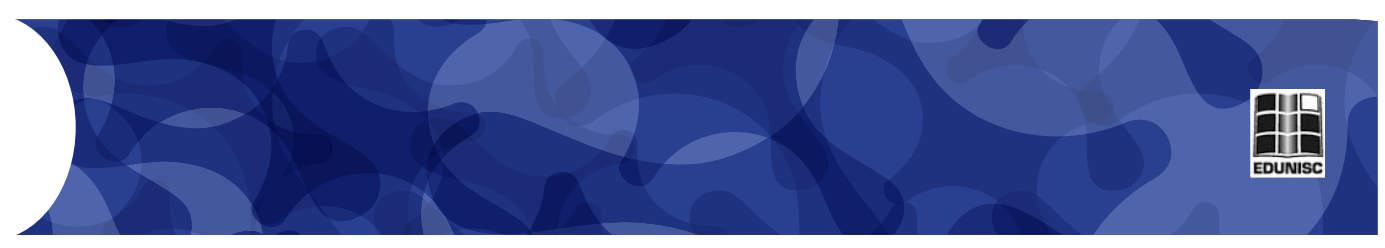

por Bakhtin (2002). Percebe-se, também, que "o indivíduo se realiza apenas na medida em que sua ação (caracterizada prioritariamente pelo discurso) 0 torna visível aos outros na esfera pública: realização e visibilidade se fazem possíveis apenas com os outros. " (ARENDT apud BIROLI, 2008, p.178, grifo do autor). A relação dialógica na cibercultura possibilita a construção da liberdade humana. Segundo Arendt (2007), a liberdade é diferente da concepção de liberdade como ação individual de escolher entre as opções dadas, ou seja, a liberdade está na esfera pública e é similar ao poder de iniciar algo novo. Assim, é a "ação dos sujeitos, que se dá prioritariamente por meio do discurso, não apenas se faz possível, mas é o traço mais característico da experiência do homem no tempo". (BIROLI, 2008, p. 179).

$\mathrm{Na}$ cibercultura, assim como na sociedade, é preciso que a tecnologia possa estar a serviço do desenvolvimento, que coincide com a construção da identidade, da autonomia e da liberdade do ser humano. Não há liberdade sem possibilidade de escolhas e de um ambiente dialógico e democrático. A discussão segue com o olhar voltado aos postulados de Lévy (2011), que constituem-se em reflexões sobre as possibilidades de construção de um ambiente antropológico no ciberespaço.

\section{A inteligência coletiva: uma perspectiva de prática social no ciberespaço}

A compreensão da complexidade dos assuntos tecnológicos, bem como seu papel na história da humanidade, não é uma prática simples. Assim, talvez mais do que em outros momentos, a influência da tecnologia na sociedade possui uma relevância marcante dentre as questões que emergem na contemporaneidade.

A dinâmica da sociedade contemporânea nos "obriga a buscar outras perspectivas para pensarmos o fenômeno tecnológico, contemporâneo" (LEMOS, 2013, p. 272). Assim, pode-se dizer que:

a prosperidade das nações, das regiões, das empresas e indivíduos depende de sua capacidade de navegar no espaço do saber. A força é conferida de agora em diante pela gestão ótima dos conhecimentos, sejam eles técnicos, científicos, da ordem da comunicação ou derivem da relação ética com os outros. (LÉVY, 2011, p. 19).

A partir desse comentário, Lévy (2011) faz um convite à reflexão sobre o espaço do saber sugerindo que a função básica da tecnologia é dominar os símbolos que o ser humano utiliza na linguagem e proporcionar o enriquecimento contínuo da inteligência coletiva, que já acompanhava o sujeito social muito antes da internet, além de ampliar a capacidade cognitiva do ser humano. A inteligência coletiva ganha potência no virtual e arquiteta uma ligação estreita entre a sociedade e a internet, a partir de uma visão antropológica que busca evidenciar a relevância do ser humano na interface com 

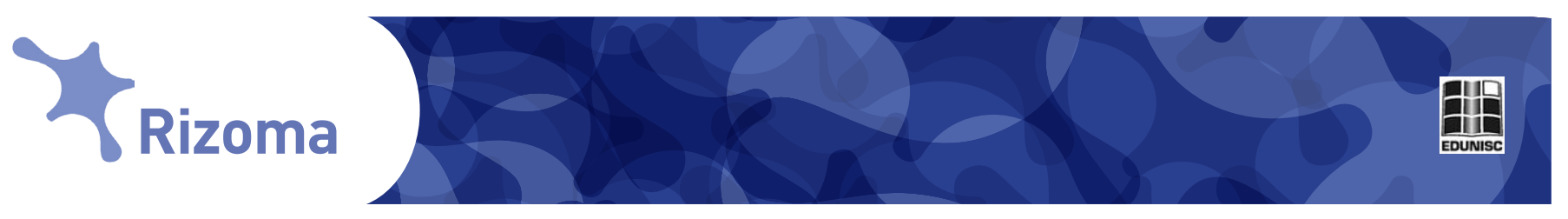

a máquina. Desse modo, a inteligência coletiva é um assunto que merece aprofundamento, para o desenvolvimento de, muito além de práticas mercadológicas, práticas sociais e educacionais.

Como já havia sido sinalizado no início deste estudo, a inteligência coletiva é uma inteligência distribuída por toda a parte. "Ninguém sabe tudo, todos sabem alguma coisa, todo o saber está na humanidade" (LÉVY, 2011, p. 29). A proposta da inteligência coletiva cria possibilidades de interação de saberes. Ao juntar saberes em prol de alguém ou algo, possibilita-se o pensamento crítico, sendo que todo o processo é mediado por interfaces virtuais. Lévy (2011) aprofunda ainda mais a ideia da inteligência coletiva quando evidencia o quesito memória expandida, possibilitada pela capacidade de armazenamento na internet.

A inteligência coletiva permite pensar-se em reconhecer as habilidades cognitivas que se distribuem nos indivíduos para que possam ser usadas nas práticas sociais da coletividade. A inteligência que acompanha o indivíduo na sociedade pode ser potencializada com a utilização das tecnologias e da comunicação no ciberespaço. O que se deve ter em mente é que as questões éticas da responsabilidade online não devem ser esquecidas. A ignorância, a redundância e a irrelevância, na rede de compartilhamentos, devem ser evitadas. A partilha de conhecimento, para que efetivamente se perceba a inteligência coletiva na prática, requer uma visão global, uma vez que, ao organizar o conhecimento na rede, o indivíduo também o organiza para os outros (LÉVY, 2011).

A inteligência coletiva já existe na natureza, entre as formigas, as abelhas e os pássaros, por exemplo, pois há, em geral nos seres vivos, uma tendência à cooperação para solucionar problemas em conjunto. A inteligência coletiva das pessoas é extraordinária, porque a linguagem as diferencia dos animais e permite a reflexão sobre si, sobre suas redes de relacionamento, por meio da uma consciência que os animais não possuem. Lévy (2011), em sua contextualização sobre a humanidade, evidencia que os seres humanos inventaram diversas linguagens e tecnologias para expressar suas formas de pensar, sentir e compartilhar conhecimento. A oralidade, a escrita, a imprensa, o digital contribuíram para o aumento da capacidade de percepção, inteligência e memória. As relações com a tecnologia de comunicação permitem uma melhora nos processos cognitivos do ser humano.

Acredita-se que, ao interagir com as plataformas digitais, o ser humano amplia as possibilidades de conexões na rede. Ao participar das redes virtuais, pode-se interagir com o outro e até mesmo influenciar a percepção do outro. Dentro desse raciocínio, os saberes estão com as pessoas e elas participam oferecendo e produzindo conhecimento. O sujeito torna-se autor, produtor, crítico, bibliotecário e curador do conhecimento. Por esse motivo, as pessoas e suas habilidades, na perspectiva de Lévy (2011), são tão valorizadas.

"Longe de fundir as inteligências individuais em uma espécie de magma indistinto, a inteligência coletiva é um processo de crescimento, de diferenciação e de retomada recíproca das singularidades" (LÉVY, 2011, p. 32). O espaço do saber construído emerge das ações individuais que constitui para o coletivo um novo ambiente virtual mais aberto, vivo e dinâmico. Jenkins (2012) converge com o pensamento de Lévy (2011), no que tange 
à inteligência coletiva possibilitar a restauração da cidadania democrática, sendo esse o raciocínio que leva a inteligência coletiva a uma utopia realizável. O momento atual permite a compreensão de que se vive um período de aprendizagem, por meio do qual modificam-se as estruturas que irão sustentar a vida política e econômica do futuro (JENKINS, 2012).

As práticas sociais que podem surgir a partir de um pensamento que se afilie ao projeto da inteligência coletiva, vão permitir que a aprendizagem colaborativa seja traduzida no compartilhamento da prática incorporada aos hábitos de cada um (exteriorizar o conhecimento tácito) com os outros usuários da rede ao mesmo tempo em que internalizarão o conhecimento explicitado. A prática explicitada torna-se implícita, ou seja, a aprendizagem ocorre a partir do que foi explicitado e exposto na rede (LÉVY, 2011).

Os estudos de Castells (2000) definem a ação comunicativa como a base da ação coletiva. O processo depende das formas de organização e da tecnologia para a possibilidade de democracia ${ }^{8}$ em sua essência. A comunicação em rede coloca a humanidade em movimento. (CASTELLS, 2000).

As discussões sobre a inteligência coletiva convergem com o conceito da linguagem como uma realidade sociocultural e interacional. Por trás da linguagem, existem pessoas e é por meio da linguagem que o ser humano entende e atua no mundo. Nesse sentido, a seguir, evidencia-se a questão metodológica deste trabalho para dar continuidade às reflexões acerca da inteligência coletiva e das questões da linguagem na ferramenta Scoop.it.
${ }^{8}$ Lévy (2011) destaca que a inteligência coletiva estaria associada à democracia. O objetivo da democracia seria de realizar e conservar a autonomia dos indivíduos. Assim, admite-se a relevância de se desenvolver um projeto civilizatório baseado na inteligência coletiva, uma vez que contribui para a preservação dos laços sociais a partir da propagação do conhecimento, do reconhecimento das singularidades e a concepção de uma democracia mais participativa.

9 A palavra cognitiva está relacionada ao processo de aquisição de conhecimento. A cognição envolve fatores diversos como o pensamento, a linguagem, a percepção, a memória, o raciocínio etc., que fazem parte do desenvolvimento intelectual.

\section{Metodologia}

A metodologia segue as recomendações de Prodanov e Freitas (2013), sendo utilizada a pesquisa exploratória com análise qualitativa. O marco teórico principal de análise da perspectiva da linguagem comunicacional é de Bakhtin (2000), e da inteligência coletiva é de Lévy (2011).

Os critérios para escolha do objeto empírico se deram em razão da disponibilidade das informações na ferramenta para a caracterização de um ambiente antropológico. Nele, os seres humanos criam e compartilham conhecimento na internet por meio da linguagem.

Optou-se pela escolha da ferramenta Scoop.it por ser uma das ferramentas online de compartilhamento de conhecimento que serve como modo de interação social entre os usuários, por meio da linguagem. A página é um instrumento no qual os usuários realizam suas atividades cognitivas ${ }^{9}$ para a utilização da inteligência coletiva em rede.

Organiza-se o estudo da seguinte forma: primeiramente, apresentamse as informações comunicacionais relativas à plataforma Scoop.it, com o intuito de caracterizar a finalidade desse espaço online. Logo após, identificam-se duas categoria teóricas: a primeira categoria é comunicação e linguagem e a segunda é inteligência coletiva. Por último, elabora-se um quadro síntese que contempla as principais evidências das categorias em análise e considerações finais. 


\section{Yrioma}

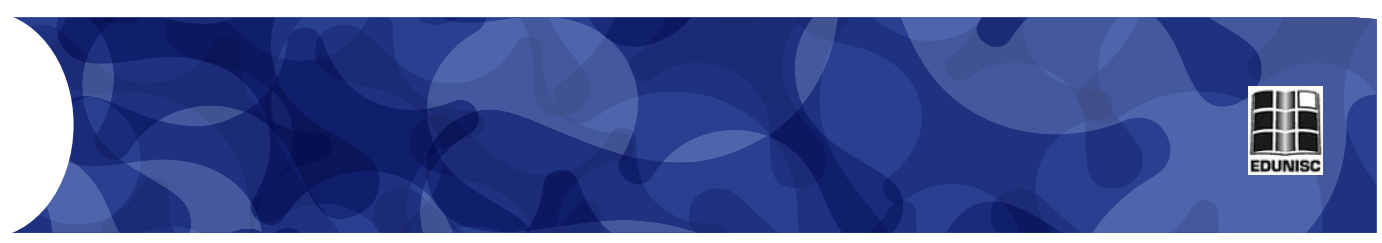

\section{Resultados e análises}

Nesta etapa, apresentam-se os recortes com informações pertinentes à caracterização da finalidade da plataforma Scoop.it.

\section{Caracterização da ferramenta Scoop.it}

O Scoop.it! é uma ferramenta disponível para implementação e compartilhamento de informações. É um serviço de curadoria ${ }^{10}$ e de partilha de monitoramento de conteúdo web sobre um assunto ou tema alvo, apresentado como um diário online, atualizável em tempo real. Seu funcionamento abrange três etapas: 1) investigação e triagem de fontes de monitoramento relativas a um assunto específico definido por diferentes palavras-chave e fontes (YouTube, Google News, Twitter, etc); 2) curadoria de conteúdos: o usuário elege as páginas da web a serem compartilhadas e essas retornarão como feeds, de acordo com os critérios de pesquisa definidos; 3) compartilhamento de inteligência: a partir das páginas que retornaram e cujo trecho pode ser consultado no Scoop.it, o usuário classifica e compartilha uma seleção em um diário que está disponível a qualquer momento, em um link indicado.

Salienta-se que a plataforma Scoop.it é uma ferramenta colaborativa que também visa ao lucro. O usuário pode se cadastrar em uma conta de acesso, sem custos, com alguns condicionamentos de níveis de acesso aos serviços. Existem dois planos de contas de acessos que são pagos pelo usuário: Pró Annual e Business Annual. Nesses planos de acesso, o usuário conta com serviços que o auxiliarão a gerenciar sua marca pessoal ou o seu site. A Figura 1 detalha os serviços disponíveis em cada plano sugerido pela ferramenta.

Figura 1 - Ferramenta Scoop. It -Planos de acesso

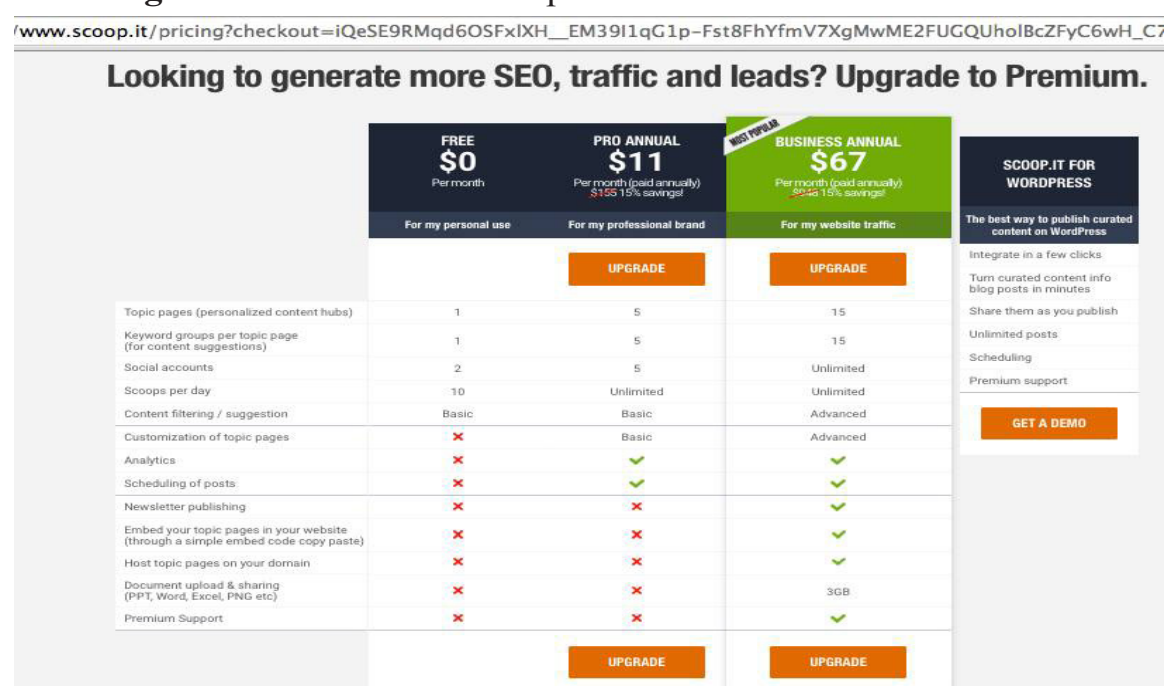

Fonte: Site da plataforma Scoop.it (2015)
${ }^{10} \mathrm{O}$ termo curadoria no contexto digital gera desdobramentos tais como curadoria de informação, de conteúdo, de conhecimento e de dados, colocando como protagonistas os indivíduos que são capazes de filtrar as informações e reorganizá-las para outros usuários, conforme Rosenbaum (2011). 


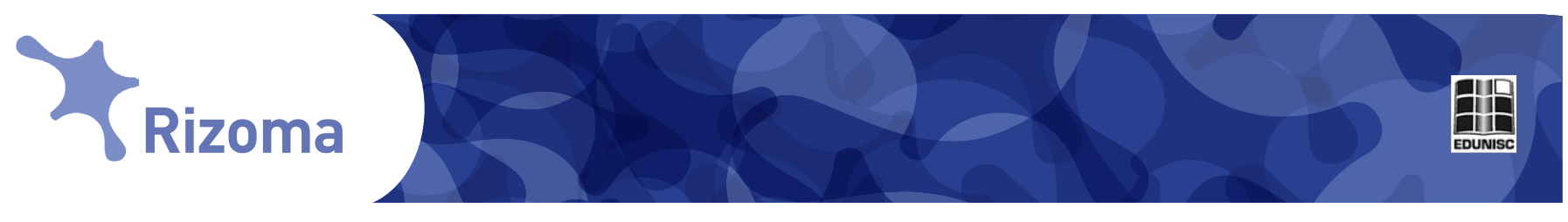

O Scoop.it ordena e acompanha os conteúdos mais significativos na internet, conforme uma série de palavras-chave estabelecidas pelo usuário. Pode-se dizer que a ferramenta é útil a todos que estão envolvidos com o monitoramento e produção de informações, como profissionais de marketing, professores, pesquisadores, blogueiros e editores da web, além do cidadão comum que pode ter uma conta gratuita no Scoop.it, apesar de alguns serviços serem pagos. A Figura 2 mostra uma captura de tela da ferramenta em análise no estudo.

Figura 2 - Ferramenta Scoop. It - Layout

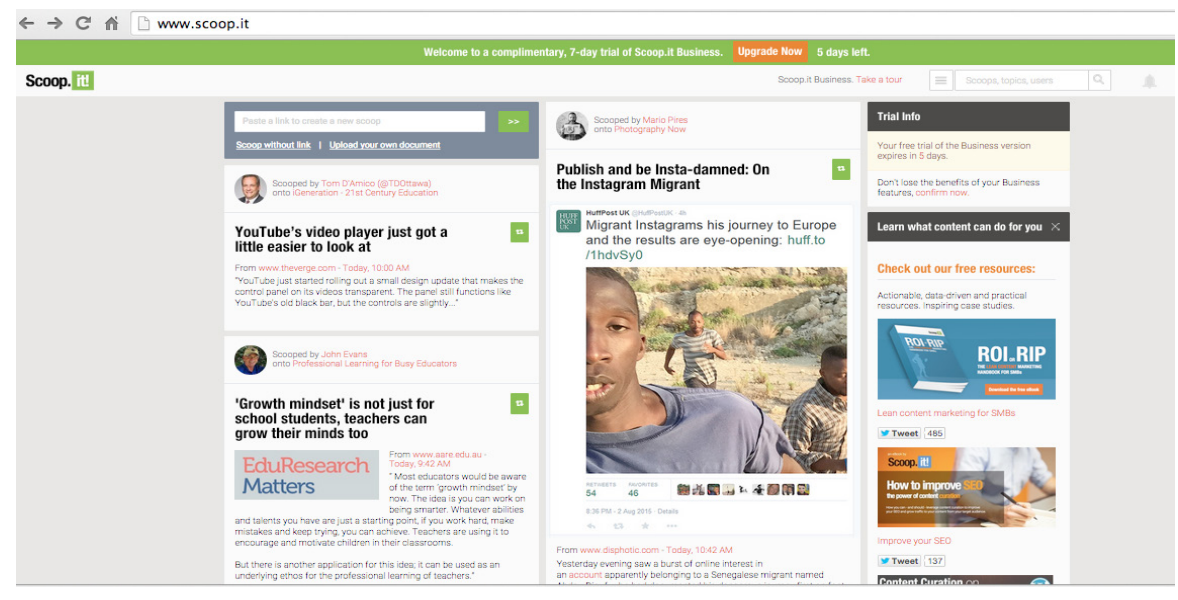

Fonte: Site da plataforma Scoop.it (2015)

A Figura 2, portanto, revela o layout e permite que o usuário tenha uma visão da plataforma onde se pode criar, compartilhar e monitorar informações na internet. No próximo item, apresenta-se a primeira categoria a ser analisada: comunicação e linguagem.

\section{Categoria de análise: comunicação e linguagem}

O Scoop.it é uma ferramenta que vem ganhando destaque, por permitir ao usuário a imersão na cultura contemporânea associada às tecnologias digitais, que criam uma nova relação entre a técnica e a vida social, o que se define como cibercultura. O Scoop.it é um exemplo da aproximação da conversa contemporânea. $\mathrm{O}$ que se percebe é que a ferramenta abre possibilidades para que se desenvolvam conhecimentos que fazem "cultivar e germinar" a distribuição e produção de conteúdo no ciberespaço.

A construção do conhecimento humano, na plataforma Scoop.it, constitui-se em um espaço de comunicação social, de organização e acesso a informações da rede ao ser favorecido por um suporte interconectado mundialmente em prol da memória do ser humano na cibercultura. $\mathrm{O}$ 


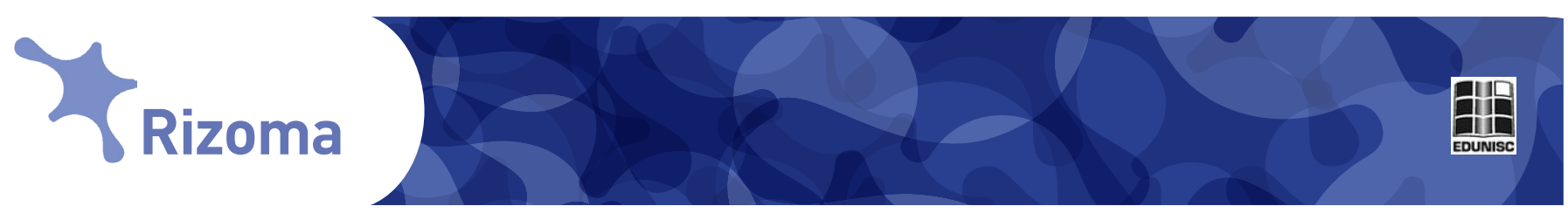

Scoop.it permite criar tópicos sobre qualquer tema, receber sugestões, seguir outros tópicos e receber sugestões de outros usuários.

A ferramenta em análise é um ambiente de interação. Desde o início da comunicação humana, ou seja, desde que começou a haver comunicação oral, escrita, alfabeto, imprensa, foi no ciberespaço que a tecnologia se potencializou e cedeu ao usuário desse tipo de plataforma de conhecimento o poder sobre suas ações e sobre seus destinos (KERCKHOVE, 1995). A ferramenta Scoop.it propicia aos sujeitos a possibilidade de construção de uma consciência individual amparada pela comunicação do coletivo. Nesse contexto, constrói-se dialogicamente, por meio da linguagem com a rede coletiva, a dimensão comunicacional no ciberespaço. Acredita-se que, mesmo que o usuário da ferramenta na internet não tenha seu parceiro comunicacional diretamente na sua frente, ao expressar-se por meio de enunciados na internet, o sujeito percebe que, ao escrever, se dirige a uma ou várias pessoas, promovendo o ato de integração dialógica a que Bakhtin (2002) se refere em sua teoria.

Nesse contexto, os usuários estimulam suas funções cognitivas. As habilidades cognitivas, por meio do Scoop.it, são potencializadas pelo virtual, visto que geram novas formas de se relacionar com a sociedade em tempo real, sendo amparadas pelas pesquisas de Lévy (2011), no que tange à expectativa da comunicação e do pensamento dos grupos humanos em benefício de um pensamento reflexivo acerca da sociedade no próximo século.

Dessa interação comunicacional, resulta uma aprendizagem coletiva, considerando o todo, porém ressaltando a importância de se ter uma consciência individual, que também é vista como um processo que liberta o ser humano e o leva à democracia. É a partir dessa visão que o homem identifica sua percepção de ser inacabado, ou seja, que necessita do outro para se constituir como pessoa e revelar-se como ser social e individual no ciberespaço.

A visibilidade e a realização do sujeito, na esfera pública, tornamse possíveis somente com os outros seres humanos (BIROLI, 2008). A linguagem, neste caso, constrói um cenário que leva a comunicação para a ação do homem no tempo, ou seja, uma comunicação que possibilita uma atitude antropológica no ciberespaço. A noção de comunicação na ferramenta Scoop.it convoca o enunciador e receptor dos enunciados à participação do ato comunicacional. Ambos fazem parte do processo, interagindo e ressignificando esse ato. Acredita-se que, por trás da linguagem, existem pessoas, e é por meio da linguagem que atuamos no mundo que está conectado em rede. A seguir, apresenta-se a segunda categoria a ser analisada: inteligência coletiva. 


\section{$Y_{\text {Rizoma }}$}

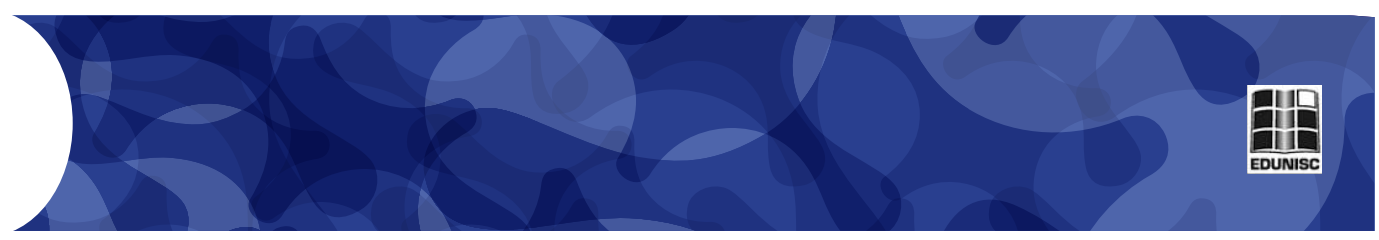

\section{Categoria de análise: inteligência coletiva}

A proposta de Lévy (2011) sobre a inteligência coletiva contextualiza a plataforma Scoop.it como uma ferramenta de curadoria de conteúdos com que podem ser reunidos os temas, as matérias mais pertinentes para alicerçar a produção, a organização e o compartilhamento online. Essa forma de construção de conhecimento evidencia que o ser humano possui uma inteligência própria que foi armazenada em suas vivências pessoais que, por isso, merecer relevo na construção da inteligência coletiva. Percebe-se que a ferramenta funciona como um modo de interação social entre os pares. O processo de transmissão e construção de ideias, que possibilita um movimento cultural e social, provoca uma nova relação entre o saber e o conhecimento chamado de cibercultura (LÉVY, 2011).

A ferramenta Scoop.it oportuniza acessar o acervo de conteúdo de forma rápida; permite a criação de um ambiente que assegura uma forma de o homem pensar e compartilhar conhecimentos com outras pessoas na internet. Na Figura 3, é possível visualizar uma tela que mostra a seleção de comunidades virtuais que alguns membros escolheram na plataforma Scoop. it para promover a partilha de conhecimentos e informações.

Figura 3 - Ferramenta Scoop. It

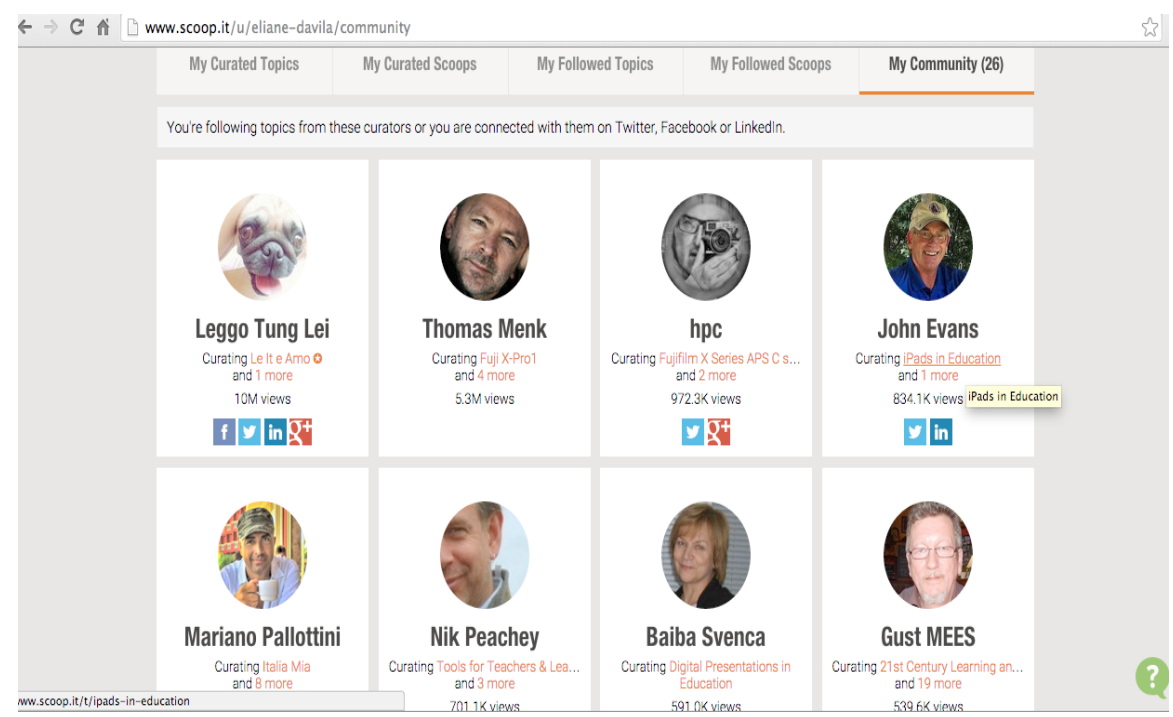

Fonte: Site da plataforma Scoop.it (2015)

A ferramenta Scoop.it pode ser considerada como uma proposta de trabalho que atende às demandas de interação, partilha e geração de conhecimento. Concorda-se com a ideia de que se vive um momento de aprendizagem, em que se modificam as estruturas que irão apoiar a vida política e econômica do futuro (JENKINS, 2012). A ferramenta está alinhada à perspectiva de que não se está, apenas, vivendo um fenômeno tecnológico, mas que existe uma construção que vai além da 

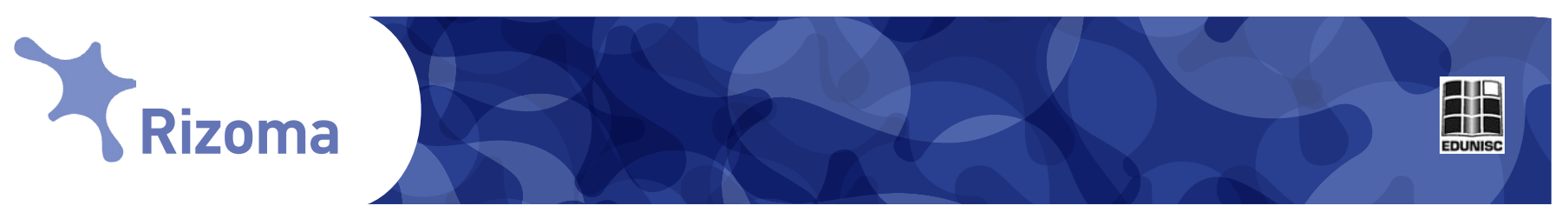

tecnologia, ou seja, há alterações na dinâmica sociocomunicacional. É possível afirmar que os usuários da plataforma constroem e reconstroem as manifestações culturais baseados em trocas e influências mútuas que vivenciam na sociedade.

A cultura contemporânea, marcada pela tecnologia, é imbricada pelas movimentações do mundo virtual, que são efetivadas pelo uso e busca de notícias em portais e ferramentas online como a Scoop.it. No ciberespaço, os seres humanos se associam eletronicamente em grupos ou redes de conhecimento e partilham experiências e preferências. As interconexões de comunidades em rede e a inteligência coletiva abarcam o crescimento das capacidades cognitivas. A ferramenta em análise sugere a colocação da humanidade em movimento (CASTELLS, 2000).

Assim, a inteligência coletiva é um fator determinante que possibilita o desenvolvimento da linguagem, do pensamento e da consciência. $\mathrm{O}$ objeto de estudo promove o movimento e a inter- relação entre esses três elementos. Ao transcender a esfera individual, uma vez que é abarcada pela esfera cultural, estabelece-se a relação de interdependência entre os sujeitos e a cultura. Verifica-se que a ferramenta em análise permite que as práticas explicitadas pelos usuários possam ser incorporadas como hábitos culturais, ou melhor, integradas por muitos usuários que a tornam novamente conhecimento implícito. Metaforicamente, é uma espécie de aprendizagem em espiral representada pelo movimento evolutivo e dialógico da inteligência coletiva.

Salienta-se que a ferramenta Scoop.it também apresenta uma visão comercial de negócio. Percebe-se, entretanto que, embora a ferramenta utilize ações de marketing e planos pagos, o agenciamento da atividade cognitiva acontece de forma independente, visto que não é a plataforma que garante a inteligência coletiva. Todos nós necessitamos de uma plataforma no ciberespaço para romper com os muros e fronteiras que o marketing nos impõe. A curadoria é um processo de autonomia do conhecimento em que se utiliza a tecnologia com finalidades humanísticas, objetivando a coerência e a responsabilidade com aquele com quem se compartilha conhecimento.

A seguir, apresenta-se uma síntese das conclusões encontradas a partir dos resultados da análise das duas categorias selecionadas.

\section{Síntese das categorias em análise}

Depreendem-se, em síntese, os principais resultados encontrados, com base nas análises das categorias eleitas para investigação. O Quadro 1 mostra uma síntese dos resultados encontrados por meio da análise da ferramenta Scoop.it. 


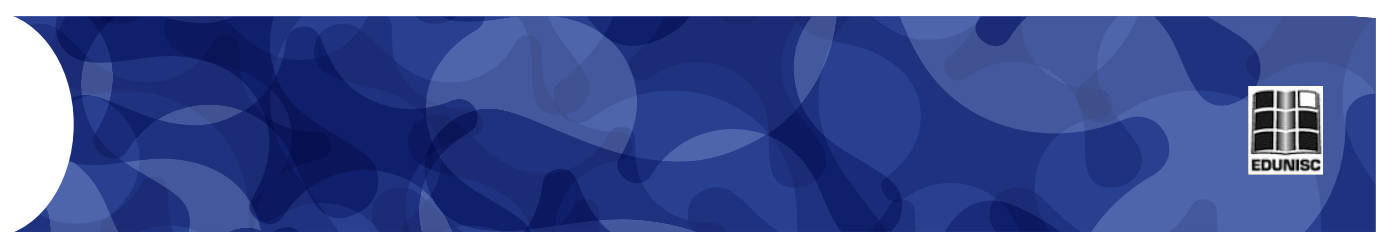

Quadro 1 - Síntese das categorias de análise

\begin{tabular}{|c|c|}
\hline COMUNICAÇÃO E LINGUAGEM & INTELIGÊNCIA COLETIVA \\
\hline $\begin{array}{l}\text { - a ferramenta possibilita o "cultivo e a germinação" } \\
\text { de conteúdo no ciberespaço; }\end{array}$ & $\begin{array}{l}\text { - ferramenta de curadoria, reunindo temas, matérias } \\
\text { para alicerçar a produção, a organização e o } \\
\text { compartilhamento online; }\end{array}$ \\
\hline $\begin{array}{l}\text { - a construção do conhecimento humano na } \\
\text { ferramenta Scoop.it constitui-se em um espaço } \\
\text { de comunicação social, de organização e acesso } \\
\text { às informações da rede, ao favorecido por um } \\
\text { suporte interconectado mundialmente, em prol } \\
\text { da memória do ser humano na cibercultura; }\end{array}$ & $\begin{array}{l}\text { - o objeto de análise funciona como um modo de } \\
\text { interação social entre os pares, visto que o processo } \\
\text { de transmissão e construção de ideias possibilita um } \\
\text { movimento cultural e social, que provoca uma nova } \\
\text { relação entre o saber e o conhecimento; }\end{array}$ \\
\hline $\begin{array}{l}\text { - as habilidades do ser humano são potencializadas } \\
\text { pelo virtual e é possível se pensar em uma } \\
\text { comunicação emprol dos grupos humanos, embusca } \\
\text { de um pensamento mais reflexivo na sociedade; }\end{array}$ & $\begin{array}{l}\text { - a ferramenta atende às demandas de interação, partilha } \\
\text { e geração de conhecimento; torna possível visualizar } \\
\text { uma alteração na dinâmica sociocomunicacional; }\end{array}$ \\
\hline - a ferramenta é interativa; & $\begin{array}{l}\text { - no ciberespaço, a ferramenta pode ser classificada } \\
\text { como provedora de interconexões de comunidades } \\
\text { em rede; coloca o ser humano em movimento no } \\
\text { espaço virtual; }\end{array}$ \\
\hline $\begin{array}{l}\text { - a ferramenta Scoop.it possibilita a construção de } \\
\text { uma consciência individual amparada pelo coletivo; }\end{array}$ & $\begin{array}{l}\text { - o objeto em análise permite o desenvolvimento da } \\
\text { linguagem, do pensamento e da consciência dos seres } \\
\text { humanos, promovendo o movimento e a interação } \\
\text { entre esses três elementos; estabelece uma relação de } \\
\text { interdependência entre o sujeito e a cultura; }\end{array}$ \\
\hline $\begin{array}{l}\text { - evidencia-se na ferramenta o ato de integração } \\
\text { dialógica entre os usuários; estimula as funções } \\
\text { cognitivas que levam à liberdade do ser humano e } \\
\text { à democracia; }\end{array}$ & $\begin{array}{l}\text { - a ferramenta permite que as práticas explicitadas } \\
\text { pelos usuários possam ser incorporadas como hábitos } \\
\text { culturais, ou melhor, integradas por muitos usuários que } \\
\text { a tornam novamente conhecimento implícito; }\end{array}$ \\
\hline $\begin{array}{l}\text { - enunciador e receptor dos conteúdos, com } \\
\text { a ferramenta Scoop.it, são convocados ao ato } \\
\text { comunicacional, interagindo e ressignificando o } \\
\text { processo. }\end{array}$ & $\begin{array}{l}\text { - metaforicamente, é uma espécie de aprendizagem } \\
\text { em espiral, representada pelo movimento evolutivo e } \\
\text { dialógico da inteligência coletiva. }\end{array}$ \\
\hline
\end{tabular}

Fonte: Elaborado pela pesquisadora (2015)

A conexão entre as duas categorias mostra a interdependência da linguagem comunicacional e da inteligência coletiva para ação reflexiva do indivíduo no ciberespaço, em prol da liberdade e da democracia do ser humano.

\section{Considerações finais}

Esse estudo tematizou a cibercultura, delimitado à análise das práticas de inteligência coletiva na e da comunicação, na ferramenta Scoop.it. Esta, por sua vez, implementa e compartilha informações no ciberespaço para geração de conhecimento na internet.

O objetivo do trabalho consistiu em refletir sobre a construção de um novo espaço antropológico, no qual os seres humanos criam e compartilham 

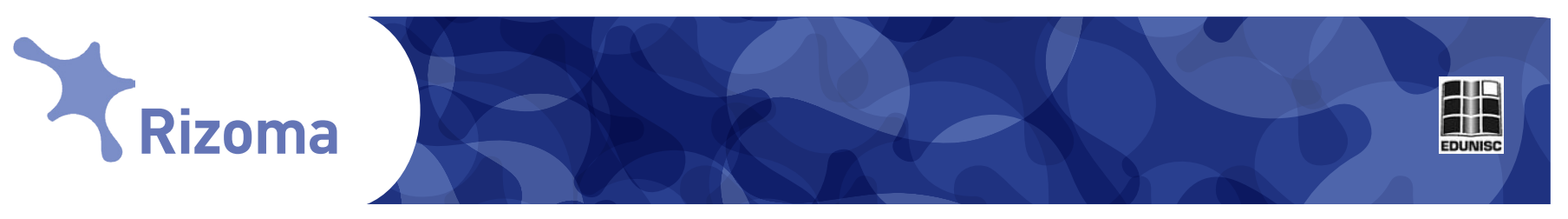

conhecimento na internet por meio da linguagem. A análise das informações direciona a resultados que apoiam a inteligência coletiva no desenvolvimento da informática, visto que a comunicação é potencializada no meio virtual, privilegiando a troca de informações entre os seres humanos. Esse ciberespaço diversificado, heterogêneo e sem um centro controlador, em que as plataformas constroem suas redes de inteligência coletiva, pode contribuir para melhorias sociais e de cultivo da inteligência individual, bem como para a inteligência em rede, uma vez que o ser humano é social e individual no uso da linguagem.

Por tudo que foi discutido, percebe-se que a inteligência coletiva pode ser entendida como uma nova economia dos seres humanos. A inteligência coletiva, ao ser praticada em ambientes virtuais, é caracterizada por novos laços sociais e por novos saberes. Vê-se isso na análise da ferramenta Scoop. it. Os resultados mostraram que, embora a plataforma se utilize de ações de marketing e se perceba um cunho comercial na cobrança de valores para se ter acesso a serviços específicos da ferramenta, os limites impostos, não impediram o agenciamento da atividade cognitiva do sujeito na ferramenta. Considera-se que a existência de uma equipe paga para fazer o serviço de curadoria, juntamente com os usuários (cidadãos comuns) da ferramenta, reforça a importância do ser humano (usuário da plataforma) ao fazer a análise crítica das fontes e evitar confiar exclusivamente em uma delas. Investigar a fonte desviar-se da manipulação e do disfarce de dados, contribuem para a mitigação da questão destacada.

Entendemos que as limitações do estudo estariam na necessidade de aprofundamento da pesquisa sobre a relação entre linguagem comunicacional e inteligência coletiva em outras ferramentas de curadoria na internet, traçando comparativos e fazendo desdobramentos dos conceitos apresentados neste estudo. Esse aspecto ficou assinalado para um possível futuro trabalho.

A realidade da inteligência coletiva no ambiente virtual requer do ser humano uma perspectiva de pensamento que revela uma ligação estreita entre a internet e a sociedade, a partir de uma visão antropológica. Nota-se que é de fundamental importância que se tenha consciência de que tudo que é feito na curadoria digital influenciará a memória coletiva dos sujeitos. Todos os usuários de plataformas colaborativas têm o poder de construir-se e de contribuir para o conhecimento de outros usuários. Com responsabilidade, é preciso ter consciência dos impactos que se pode ter sobre o semelhante. Em um cenário virtual, é de extrema relevância que se conheça as novas regras na produção do conhecimento e os novos papéis dos sujeitos no ciberespaço.

A tecnologia, mesmo a de vanguarda, não é a única responsável pela construção de novas formas de saberes e de contribuir para uma inteligência coletiva. O homem, por meio de suas habilidades cognitivas e de linguagem, é o protagonista do espaço virtual que influencia e é influenciado pela sociedade contemporânea. Enfim, a interação entre o homem e a máquina é muito inspiradora e enriquecedora, mas é preciso que o homem seja mais inteligente e não as máquinas. 


\section{$Y_{\text {Rizoma }}$}

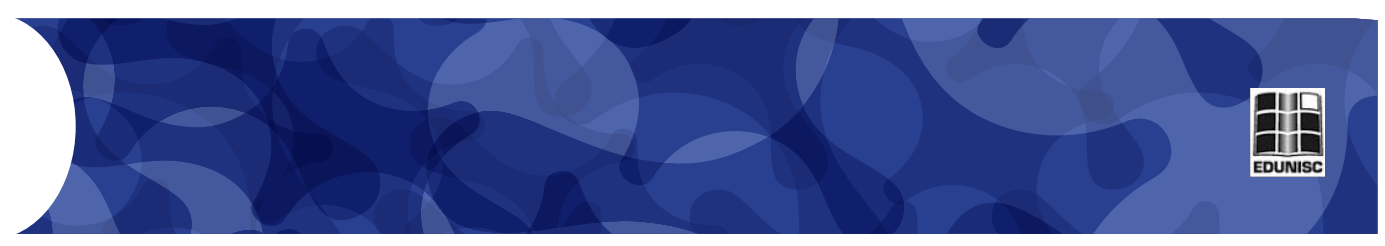

\section{Referências}

ARENDT, Hannah. A condição humana. 10. ed. Rio de Janeiro: Forense Universitária, 2007.

BAKHTIN, Mikhail. Estética da criação verbal. Tradução: Maria Ermantina Galvão; revisão da tradução Marina Appenzeller. 3. ed. São Paulo: Martins Fontes, 2000.

- Marxismo e filosofia da linguagem: problemas fundamentais do método sociológico na ciência da linguagem. São Paulo: Hucitec, 2002.

BIROLI, Flávia. Dizer (n)o tempo: observações sobre história, historicidade e discurso. In: SIGNORINI, Inês (Org.). [Re]discutir texto, gênero e discurso. São Paulo: Parábola Editorial, 2008. p. 157-184.

BOSI, Alfredo. Diáletica da colonização. 2 ed. São Paulo: Companhia das letras, 1992.

CASTELlS, Manuel. A sociedade em rede. São Paulo: Paz e Terra, 2000.

CHARAUDEAU, Patrick. Discurso das mídias. São Paulo, SP: Contexto, 2009.

FERRAMENTA SCOOP. IT. Disponível em: <http://www.scoop.it/>. Acesso:em 07 ago. 2015.

JENKINS, Henry. Cultura da convergência. São Paulo: Aleph, 2Ed, 2012.

KERCKHOVE, Derrick de. A pele da cultura: uma investigação sobre a nova realidade eletrônica. Lisboa: Relógio D’Água, 1995.

LEMOS, André. Cibercultura: tecnologia e vida social na cultura contemporânea. Sulina, Porto Alegre, 2013.

LÉVY, Pierre. A inteligência coletiva: por uma antropologia do ciberespaço.

8. Ed. São Paulo: Edições Loyola, 2011.

MCLUHAN, Marshall. Os meios de comunicação como extensão do homem. Tradução de Décio Pignatari. 9 ed. São Paulo: Cultrix, 1998.

PRODANOV, C. C.; FREITAS, E. C. de. Metodologia do trabalho científico: métodos e técnicas da pesquisa e do trabalho acadêmico. 2. ed. Novo Hamburgo: Feevale, 2013. Disponível em: <http://docente.ifrn.edu. 

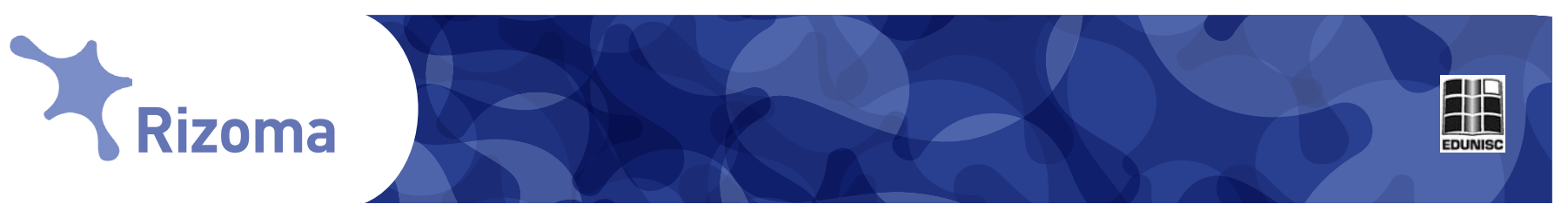

br/valcinetemacedo/disciplinas/metodologia-do-trabalho-cientifico/e-bookmtc > . Acesso em: 07 ago. 2015.

RIBEIRO, A. P. G.; SACRAMENTO, I. Mikhail Bakhtin e os estudos da comunicação. In: Mikhail Bakhtin: linguagem, cultura e mídia.

(Orgs.). São Carlos: Pedro \& João Editores, 2010. p. 09-34.

ROSENBAUM, Steven. Curation nation: how to win in a worls where consumers are creators. New York:McGrawHill, 2011. 